\title{
Exploring the Relationship between Partnership Model Participation and Interfirm Network Structure: An Analysis of the Office365 Ecosystem
}

Joey van Angeren - Eindhoven University of Technology Slinger Jansen - Utrecht University Sjaak Brinkkemper - Utrecht University

Joey van Angeren, Slinger Jansen \& Sjaak Brinkkemper. Exploring the Relationship between Partnership Model Participation and Interfirm Network Structure: An Analysis of the Office365 Ecosystem. In Proceedings of the Fifth International Conference on Software Business. 


\section{Outline}

- Introduction to platform ecosystems

- Ecosystem governance and partnership models

- Research question

- Microsoft Office365

- Research approach

- Results

- Crafting propositions

- Discussion, conclusion and future research 


\section{Industry platforms}

A product, service or technology, that is developed by one or several firms, that serves as a foundation upon which other firms can build complementary products, services or technologies.

Gawer (2009)

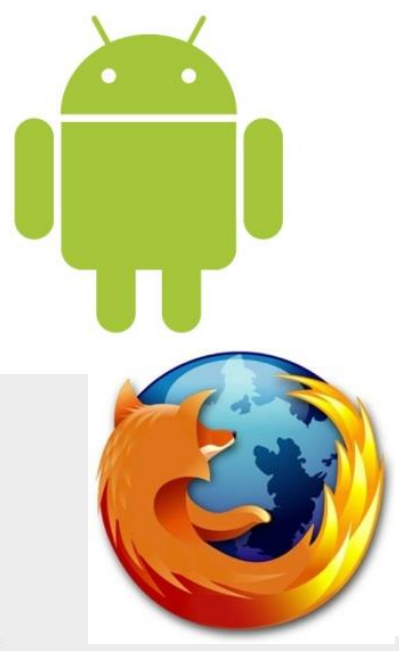

Windows 8

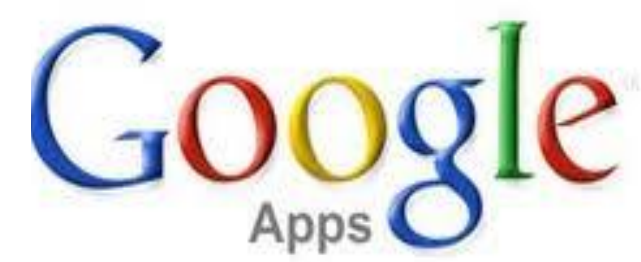




\section{Proprietary/commercial platform ecosystems}

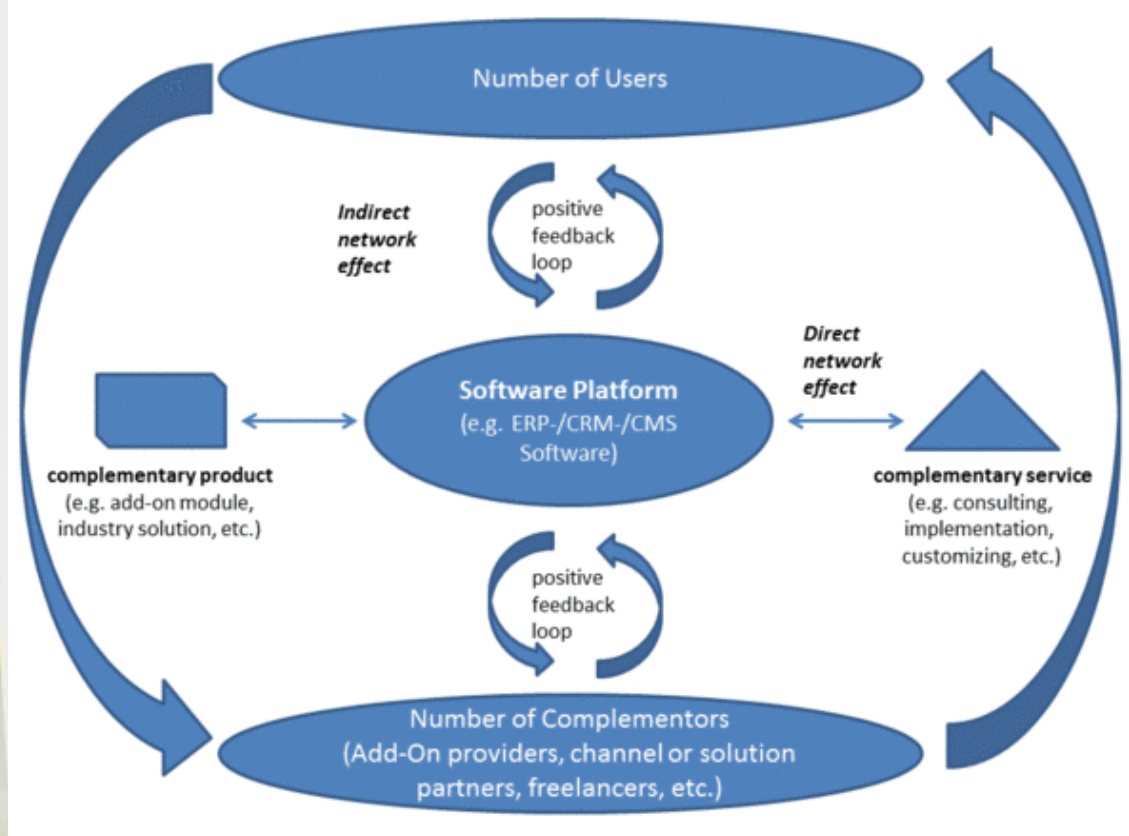

Cusumano (2010)
- Proprietary software platform: a software platform that is closed-source and owned by a single for-profit entity

- Platform ecosystem: all interlinked complementors or the interlinked set of products and services they develop

- Members of a platform ecosystem are loosely coupled: less formal interfirm relationships such as product certification, technological partnerships and shared marketing link complementors both among each other and to the platform owner 


\section{Network effects and the role of the platform owner}

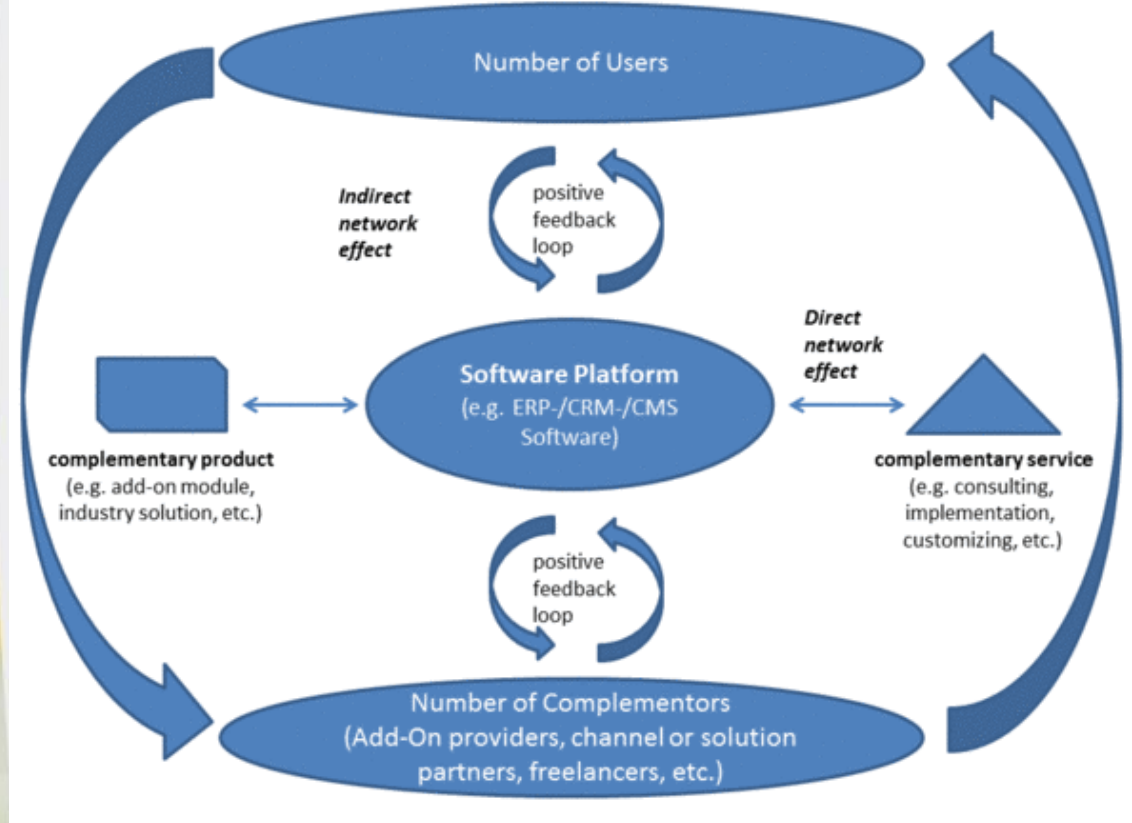

Cusumano (2010) 


\section{Ecosystem governance}

Ecosystem governance: procedures and processes by which a company controls, changes or maintains its current or future position in a software ecosystem.

\begin{tabular}{|c|c|c|}
\hline & \multicolumn{2}{|c|}{ Software (service) platform } \\
\hline & Community & Private Entity \\
\hline$\frac{9}{\frac{c}{0}}$ & $\begin{array}{l}\text { Expand applicability } \\
\text { Make strategy explicit } \\
\text { Create APIs } \\
\text { Do co-development } \\
\text { Contrib to comp. platforms }\end{array}$ & $\begin{array}{l}\text { Expand applicability } \\
\text { Make strategy explicit } \\
\text { Create APls } \\
\text { Do co-development } \\
\text { Dev. complementary platforms } \\
\text { Develop new business models }\end{array}$ \\
\hline 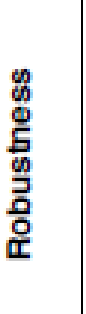 & $\begin{array}{l}\text { Form consortium } \\
\text { Grow consortium } \\
\text { Create subgroups } \\
\text { Raise entry barriers } \\
\text { Form alliances } \\
\text { Stabilize APIs } \\
\text { Make consortium explicit } \\
\text { Open up governance }\end{array}$ & $\begin{array}{l}\text { Create partnership model } \\
\text { Do marketing } \\
\text { Grow profits } \\
\text { Partner development programs } \\
\text { Form alliances } \\
\text { Stabilize APIs } \\
\text { Raise entry barriers } \\
\text { Make partners explicit } \\
\text { Propagate operation knowledge }\end{array}$ \\
\hline 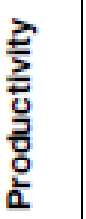 & $\begin{array}{l}\text { Organize dev days } \\
\text { Create knowledge hubs } \\
\text { Participate in contests }\end{array}$ & $\begin{array}{l}\text { Organize dev days } \\
\text { Collaborative marketing } \\
\text { Create sales partner program } \\
\text { Create new sales channels }\end{array}$ \\
\hline
\end{tabular}




\section{Partnership models}

- Complementor pays (e.g., monetary fees, requirements) to fulfill role as partner in the Microsoft Certified Partner Network

- Predefined benefits attract potential partners to join

- Locus of control

- Product certification

- Partner development

- Fosters lock-ins

- Enforce platform exclusivity

- Relational lock-in (strong tie with Microsoft)

Microsoft Partner

Gold Customer Relationship Management Gold Small Business

Gold Midmarket Solution Provider

Gold Volume Licensing 


\section{Triggers and relevance}

- Triggers:

- Little research on ecosystem governance, the effect of ecosystem governance processes remains unknown

- Little research considers proprietary platform ecosystems

- No insight into the extent to which complementors interact

- Relevance:

- Develop a method to visualize and analyze proprietary platform ecosystems

- Insight into the factors that shape the structure of proprietary platform ecosystems

- Aid platform owners in analyzing their own ecosystem and the assessing impact that their ecosystem governance might have 


\section{Research question}

What is the influence of complementor lock-ins on the network structure of a proprietary platform ecosystem? 


\section{Microsoft Office 365}

- The platform: cloud-based productivity suite

- Contains: individually customizable versions of Microsoft Exchange, Microsoft Lync, Microsoft Office, Microsoft SharePoint

- Intended for: small to medium-sized enterprises, governmental and educational institutions

- Examples of third-party application development: integration with other platforms, cloud migration functionality, CRM and ERP, business templates for Microsoft Office

- App store: Office365 Marketplace (Part of the bigger Microsoft PinPoint app store)

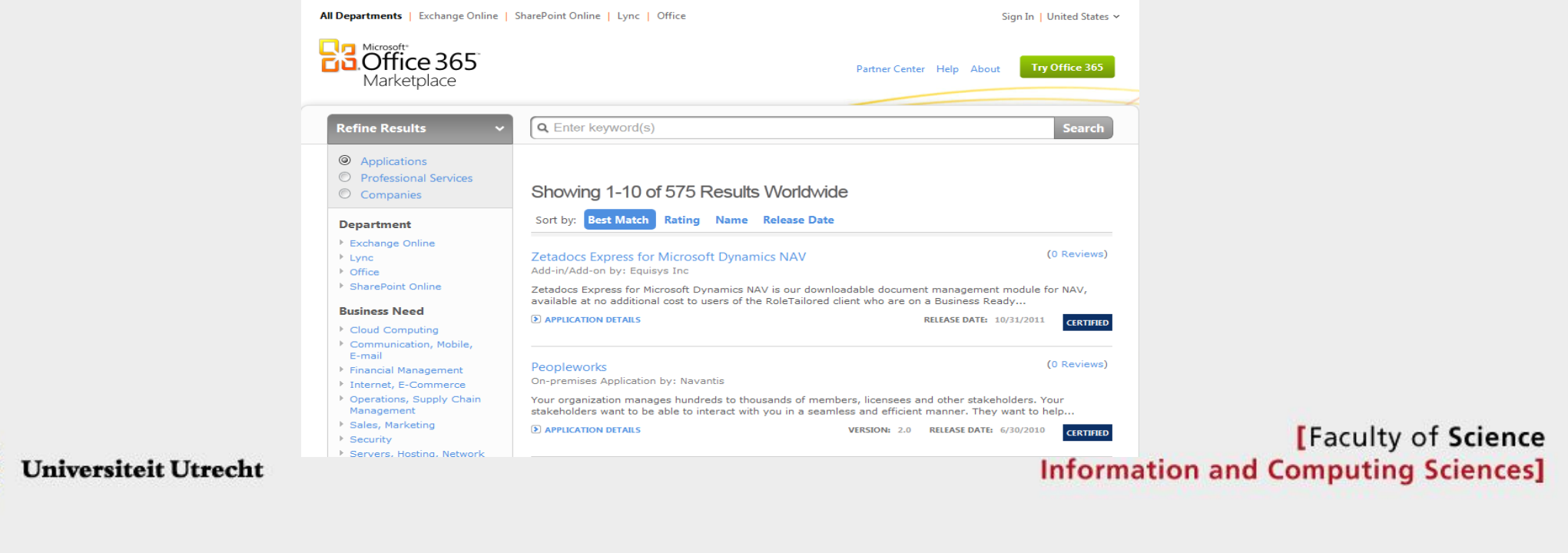




\section{Data collection}

- Identification of Microsoft Office365 complementors:

- Automated data extraction from the Office365 Marketplace by means of a web crawler

- Iterative retrieval from global and $\mathbf{5 9}$ regional versions of the Office365 Marketplace

- Applications listed under category 'Applications', professional services and on-premises apps were excluded

- Manual cleansing of dataset to remove or merge duplicated entries: Mostly duplicated listing of applications (global and regional)

- Identification of interfirm relationships:

- Obtained by means of manually traversing complementor websites, usually mentioned 1: presence of interfirm relationship under 'Partner' tab and CrunchBase

- Interfirm relationships treated as symmetric ties $\left(a^{i j}=a^{j i}\right)$

- Identified relationships maintained in adjacency matrix

0 : absence of relationship

\begin{tabular}{|l|lllllll|}
\hline & Google & $\begin{array}{l}\text { Zoho } \\
\text { Corp. }\end{array}$ & SaaSt & $\begin{array}{l}\text { Top- } \\
\text { SolutionsWork }\end{array}$ & $\begin{array}{l}\text { Cloud- } \\
\text { sym }\end{array}$ & $\begin{array}{l}\text { florey- } \\
\text { soft }\end{array}$ \\
\hline ed Google & - & 1 & 1 & 1 & 1 & 1 & 1 \\
Zoho Corp. & 1 & - & 0 & 1 & 0 & 0 & 0 \\
SaaSt & 1 & 0 & - & 0 & 0 & 0 & 0 \\
TopSolutions & 1 & 1 & 0 & - & 0 & 0 & 0 \\
CloudWork & 1 & 0 & 0 & 0 & - & 0 & 0 \\
ektosym & 1 & 0 & 0 & 0 & 0 & - & 1 \\
floreysoft & 1 & 0 & 0 & 0 & 0 & 1 & - \\
\hline
\end{tabular}

Van Angeren et al. (2013) 


\section{Data analysis}

- Inductive and exploratory study

- (Social) network analysis (nodes represent members of the ecosystem, edges represent the interfirm relationships among them)

- Statistical inference 


\section{Descriptives}

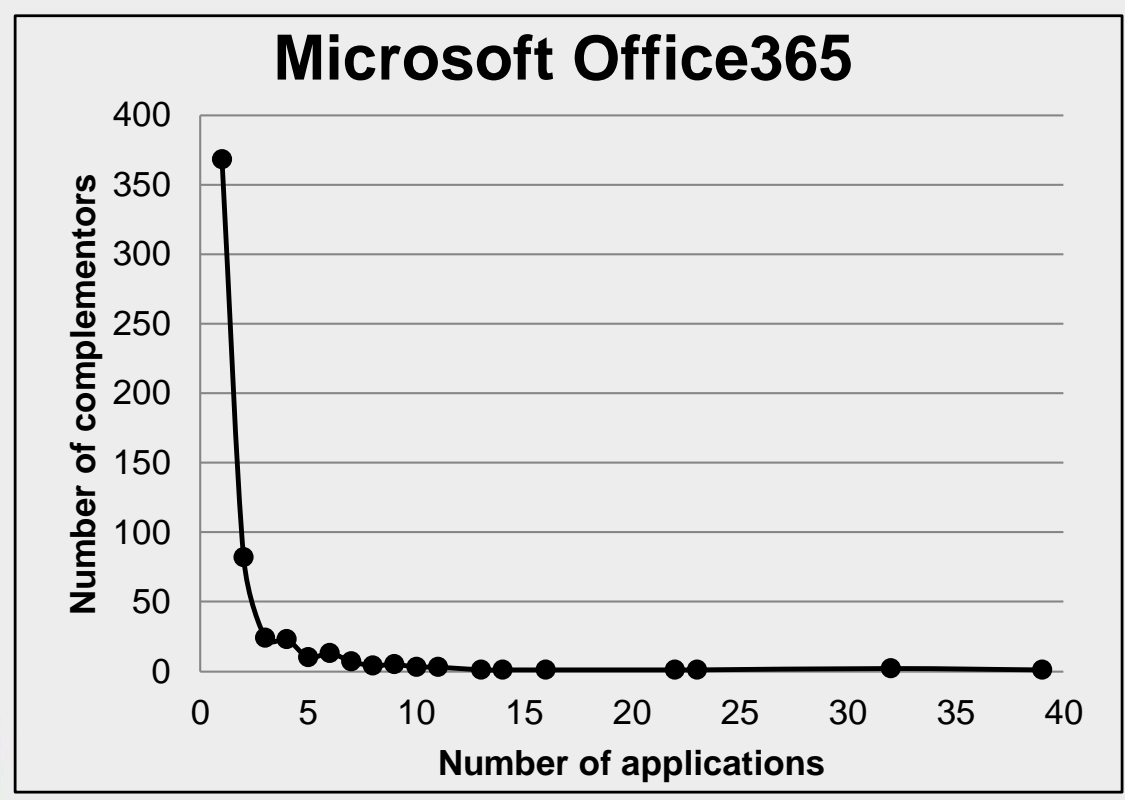

- Data collected at 13-02-2013

- 1204 applications

- 550 complementors

- Microsoft itself does not enter complementary markets

- Average of $\mathbf{2 . 1 8}$ applications per complementor (Std. Dev 1.65)

- $\mathbf{5 0 . 5 0 \% ~ ( 2 7 8 ) ~ c o m p l e m e n t o r s ~}$ participates in Microsoft Certified Partner Network 


\section{The Microsoft Office365 ecosystem}

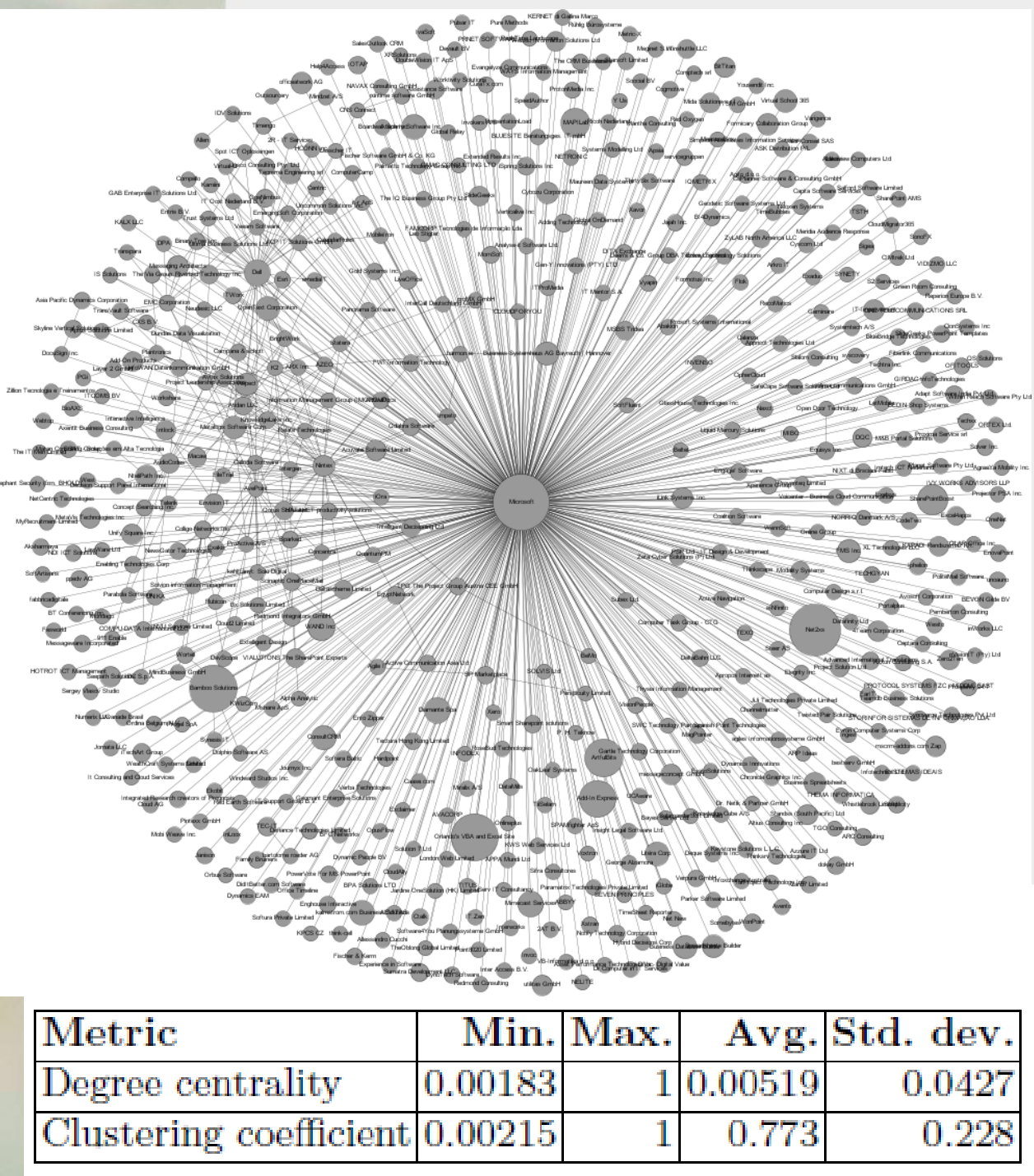

\begin{tabular}{|l|r|r|r|r|}
\hline Metric & Min. & Max. & Avg. & Std. dev. \\
\hline Degree centrality & 0.00183 & 1 & 0.00519 & 0.0427 \\
\hline Clustering coefficient & 0.00215 & 1 & 0.773 & 0.228 \\
\hline
\end{tabular}

Universiteit Utrecht
- 787 interfirm relationships

- Average of 1.43 interfirm relationships per complementor

- Hub-and-spoke network topology

- Small number of well connected complementors

\begin{tabular}{|l|r|}
\hline Metric & Value \\
\hline Size & 551 \\
\hline Network density & 0.00500 \\
\hline Centralization & 0.9984 \\
\hline Modularity & 0.336 \\
\hline Clustering coefficient & 0.773 \\
\hline
\end{tabular}




\section{Underlying network topology}

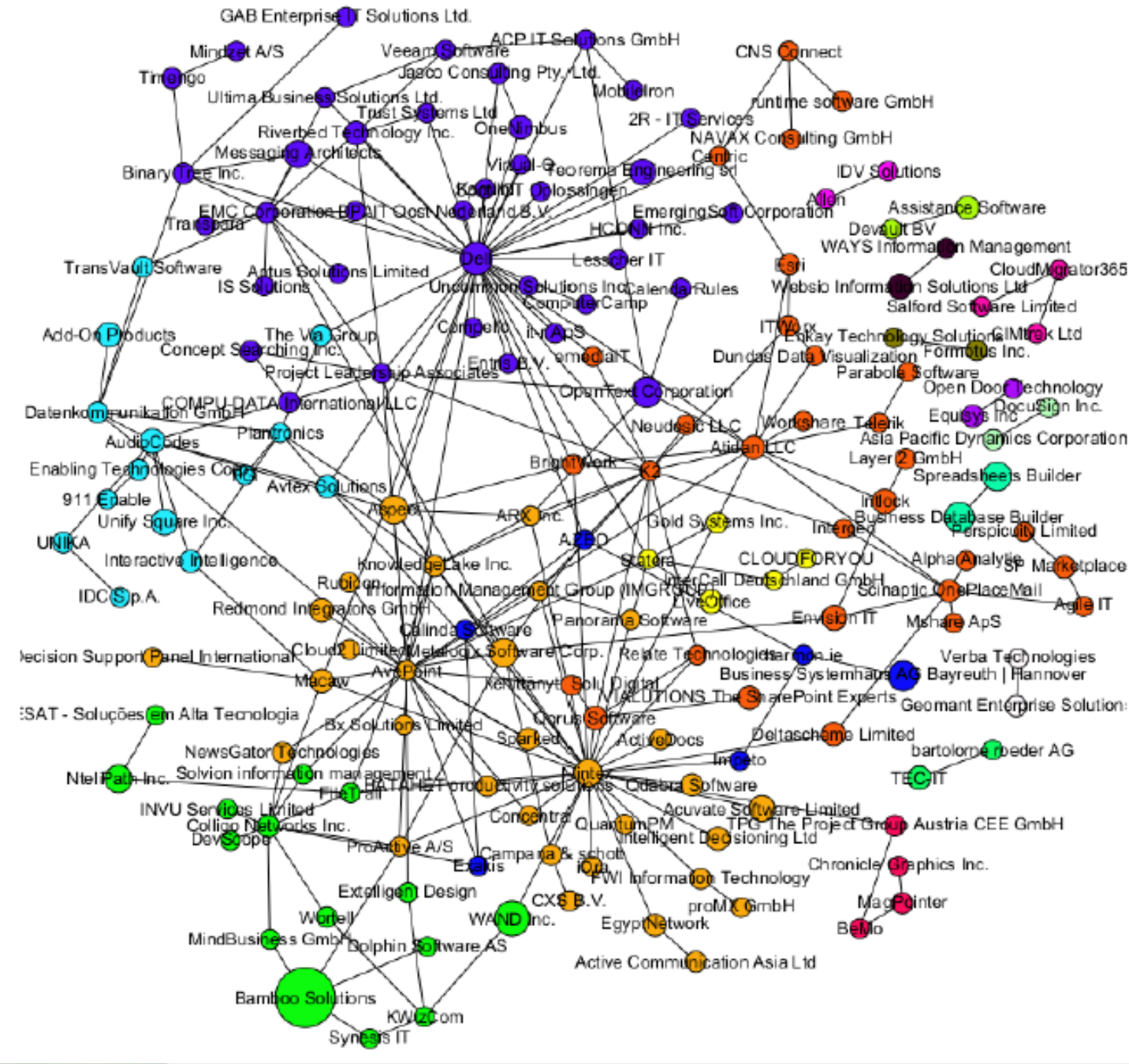

- Data cleansing to uncover network topology underneath hub-andspoke network

- Cleansing steps:

- Remove actors solely connected to Microsoft

- Remove Microsoft

- Cluster detection by means of the modularity algorithm (Blondel et al., 2008)

- Apart from the dyads on the right side of the figure, clusters are interconnected 
Analysis: Complementor productivity and

- More productive embeddedness

complementors are better embedded

- Increasing development activity and growing number of interfirm relationships coincide (positive correlation) because:

Relevant descriptives

- Principal complementor: access to resources, exert influence

\begin{tabular}{llll}
$\begin{array}{l}\text { Average \# of } \\
\text { applications }\end{array}$ & $\begin{array}{l}\% \text { of comple- } \\
\text { mentors with } \\
\text { 1 application }\end{array}$ & $\begin{array}{l}\text { Average \# of } \\
\text { relationships }\end{array}$ & $\begin{array}{l}\% \text { of } \\
\text { complemen- } \\
\text { tors with } \\
\text { relationships }\end{array}$ \\
\hline 2.18 & $66.85 \%$ & 1.43 & $29.82 \%$ \\
\hline
\end{tabular}

- New entrant: tie with principal complementor increases market visibility, achieve chain of interoperability

- The platform owner benefits: increased stability of the ecosystem, relational lock-ins

Correlations

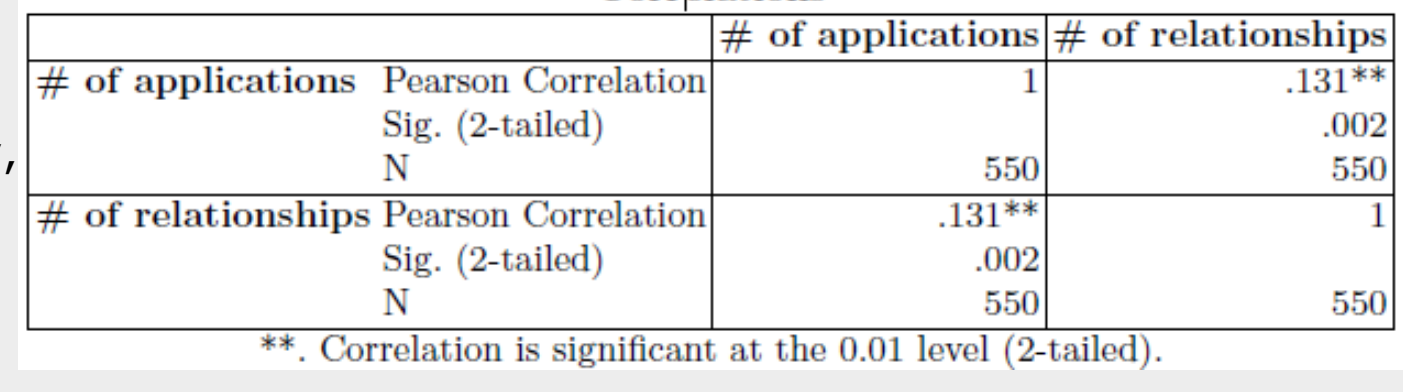

Proposition: The number of applications developed by a complementor will be positively related to the number of interfirm relationships that it initiates. 


\section{Analysis: partnership model participation}

- Partner development by Microsoft as means to foster complementor interconnectivity and productivity?

- Interconnectivity: developer and partner conferences, partner directory, active matchmaking between partners by Microsoft, ...

- Productivity: Niche creation, access to customers, cocreation between partner and Microsoft, sales partner program, ...

- Complementor age (date since publishing first application in Office365 Marketplace) not significantly different across groups

\begin{tabular}{lll|llll} 
Variable & Group & $\mathbf{N}$ & Mean & Std. Dev. & t & Sig \\
\hline $\begin{array}{l}\text { Age of } \\
\text { complementor } \\
\text { (in years) }\end{array}$ & Partner & 175 & 2.693 & 0.856 & & \\
\hline & $\begin{array}{l}\text { Non- } \\
\text { partner }\end{array}$ & 175 & 2.588 & 1.056 & 0.593 & 0.728
\end{tabular}

\section{Relevant descriptives}

\begin{tabular}{|lll|}
$\begin{array}{l}\text { Average \# of } \\
\text { applications }\end{array}$ & $\begin{array}{l}\text { Average \# of } \\
\text { relationships }\end{array}$ & $\begin{array}{l}\text { Partnership } \\
\text { model coverage }\end{array}$ \\
\hline 2.18 & 1.43 & $50.50 \%$ \\
\hline
\end{tabular}

\section{Independent samples t-test}




\section{Analysis: partnership model participation}

- Partner development by Microsoft as means to foster complementor interconnectivity and productivity?

- Independent samples t-test:

- Relationships: Microsoft partners have significantly more interfirm relationships

Proposition: Fostering complementor lock-ins will be positively related to the network density of a proprietary platform ecosystem.

Proposition: Fostering complementor lock-ins will not influence the productivity of a proprietary platform ecosystem.

- Applications: Microsoft partners do not develop significantly more applications

- Partner enablement positively related to network density, while developer scope remains unaffected

Independent samples t-test

\begin{tabular}{|lllllll|}
\hline Variable & Group & N & Mean & $\begin{array}{l}\text { Std. } \\
\text { Dev. }\end{array}$ & t & Sig \\
\hline $\begin{array}{l}\text { \# of } \\
\text { relationships }\end{array}$ & Partner & 278 & 1.192 & 2.925 & & \\
\hline & $\begin{array}{l}\text { Non- } \\
\text { partner }\end{array}$ & 272 & 0.522 & 2.509 & 2.895 & $0.004 * * *$ \\
\hline $\begin{array}{l}\text { \# of } \\
\text { applications }\end{array}$ & Partner & 278 & 2.313 & 3.351 & & \\
\hline & $\begin{array}{l}\text { Non- } \\
\text { partner }\end{array}$ & 272 & 2.063 & 3.390 & 0.871 & 0.384 \\
\hline
\end{tabular}

$* * *$, correlation is significant at $p<0.001 \quad$ [Faculty of Science 


\section{Discussion and conclusion}

- The Microsoft Office365 ecosystem is a hub-and-spoke network

- 550 complementors that developed 1204 applications (2.18 applications per complementor)

- 787 initiated interfirm relationships (1.43 per complementor)

- The number of applications a complementor develops is positively related to the number of interfirm relationships it initiates

- Lock-ins

- Are positively related to the network density a proprietary platform ecosystem

- Appear to be unlikely to force complementors beyond their development scope

- Limitations

- Reliance on proprietary sources: Not all complementors provide access to partner listings

- Alternative explanations for observed effects, influence of established SharePoint developers (on-premises platform launched in 2001), (im)maturity of the ecosystem, multi-homing 


\section{Directions for future research}

- Inclusion of service providers for 'structural hole analysis': niche detection for service providers in the ecosystem

- Longitudinal studies of platform ecosystems to observe causal effects

- More fine-grained exploration of platform ecosystems (e.g., multiplex perspective on interfirm relationships, multiple measures for governance, ...)

- Comparison of multiple platform ecosystems (e.g., similar platform, same platform owner, same governance, different governance, ...)

- Towards automation of ecosystem analysis to aid practitioners in selecting and analyzing ecosystems 


\section{References}

Angeren, J. van, Kabbedijk, J., Popp, K.M. (2013). Managing software ecosystems through partnering. In S. Jansen, S. Brinkkemper \& M.A. Cusumano (Eds.), Software Ecosystems: Analyzing and Managing Business Networks in the Software Industry (pp. 85-102). Cheltenham, UK: Edward Elgar Publishing.

Angeren, J. Van, Blijleven, V., Jansen, S., \& Brinkkemper, S. (2013). Complementor Embeddedness in Platform Ecosystems: The Case of Google Apps. Proceedings of the Seventh International Conference on Digital EcoSystems and Technologies, 37-42.

Blondel, V., Guillaume, J., Lambiotte, R., \& Lefebvre, E. (2008). Fast unfolding of communities in large networks. Journal of Statistical Mechanics, 5(10).

Boudreau, K.J. (2012). Let a Thousand Flowers Bloom? An Early Look at Large Numbers of Software App Developers and Patterns of Innovation. Organization Science, 23(5), 1409-1427.

Cusumano, M.A. (2010). Staying power: Six enduring principles for managing strategy in an uncertain world. New York, NY, USA: Oxford University Press.

Hartigh, E., Tol, M., \& Visscher, W. (2006). The health measurement of a business ecosystem. Proceedings of the European Network on Chaos and Complexity Reesearch and Management Meeting.

Gawer, A. (2009). Platform dynamics and strategies: From products to services. In A. Gawer (Ed.), Platforms, Markets and Innovation (pp. 45-76). Cheltenham, UK: Edward Elgar Publishing.

Iansiti, M., \& Levien, R. (2004). Strategy as Ecology. Harvard Business Review, 82(3), 68-78.

Jansen, S., \& Cusumano, M.A. (2013). Defining software ecosystems: a survey of software platforms and business network governance. In S. Jansen, S. Brinkkemper \& M.A. Cusumano (Eds.), Software Ecosystems: Analyzing and Managing Business Networks in the Software Industry (pp. 13-28). Cheltenham, UK: Edward Elgar Publishing.

Popp, K.M. (2010). Goals of software vendors for partner ecosystems - a pracititoners' view. Proceedings of the First International Conference on Software Business, 181-186. 